\title{
Cultura y movilización social contra la violencia sexual a través de Twitter: el caso del fallo judicial "\#LaManada" en España
}

\section{Culture and social mobilisation against sexual violence via Twitter: the case of the "\#LaManada" court ruling in Spain}

Asunción Bernárdez-Rodal. Universidad Complutense de Madrid. España.

asbernar@ucm.es

$[\mathrm{CV}] \odot \mathrm{R}^{\mathrm{C}} \mathrm{O}$

Nuria López-Priego. Universidad Complutense de Madrid. España.

nurlop03@ucm.es

[CV] (D)

Graciela Padilla-Castillo. Universidad Complutense de Madrid. España.

gracielp@ucm.es

[CV] $\mathrm{C} \mathrm{R}^{\mathrm{T}} \mathrm{O}$

Proyecto de I+D+i, Programa de Excelencia, Subprograma Estatal de generación de conocimiento. Ministerio de Economía, Industria y Competitividad. Referencia: FEM2017-83302-C3-3-P. Producción Cultural en redes sociales: industria, consumo popular y alfabetización audiovisual de la juventud española con perspectiva de género (2018-2022).

Cómo citar este artículo / Referencia normalizada

Bernárdez-Rodal, A.; López-Priego, N.; Padilla-Castillo, G. (2021). Cultura y movilización social contra la violencia sexual a través de Twitter: el caso del fallo judicial "\#LaManada" en España. Revista Latina de Comunicación Social, 79, 237-262. https://www.doi.org/10.4185/RLCS-2021-1502

\section{RESUMEN}

Introducción. Este artículo analiza la difusión de tuits críticos de uno de los fallos judiciales más controvertidos y ampliamente publicitados en la historia española, que determinó que un grupo de hombres era culpable de abuso en lugar del delito de violación más grave, en 2018. Metodología. El estudio utilizó un método mixto de enfoque cuantitativo y cualitativo, con un corpus para el análisis de 73.904 tuits. Resultados. Del número total de tuits obtenidos, $49.886(67,5 \%)$ fueron retuits, mientras que el otro $32,5 \%$ fueron mensajes originales con o sin menciones de otros usuarios y respuestas a otros tuits. Conclusiones. Las conclusiones que se extraen son que Twitter ha llegado a ser reconocida como la red social para expresar indignación política y que las protestas sociales en la red están asociadas con procesos de militancia y movimiento feminista. El anonimato en estas plataformas tiende 
a ser visto como una oportunidad para expresar libremente ideas y opiniones que, de otro modo, serían imposibles de difundir.

PALABRAS CLAVE: Movilización política; activismo digital; agresión sexual; violación; Twitter; feminismo; crimen.

\begin{abstract}
Introduction. This article analyses the dissemination of tweets critical of one of the most controversial and widely publicised court rulings in Spanish history, which found a group of men guilty of abuse rather than the more serious crime of rape in 2018. Methodology. The study used a mixed method of quantitative and qualitative approaches, with a corpus for analysis of 73,904 tweets. Results. Of the total number of tweets obtained, 49,886 (67.5\%) were retweets, while the other $32.5 \%$ were original messages with or without mentions of other users and replies to other tweets. Conclusions. The conclusions drawn are that Twitter has come to be recognised as the social network for expressing political outrage, and that the social protests on the network are associated with processes of militancy and feminist movement. Anonymity on these platforms tends to be viewed as an opportunity to freely express ideas and opinions that would otherwise be impossible to disseminate.
\end{abstract}

KEYWORDS: Political mobilisation; digital activism; sexual assault; rape; Twitter; feminism; crime.

\title{
CONTENIDO
}

1. Introducción 1.1. Comienzo del fenómeno social 1.2. Cuestiones teóricas: movilización feminista y violencia sexual 2. Objetivos 3. Cuestiones metodológicas 4. Resultados 5. Usuarios más retuiteados 6. Ataque en números 7. Expertos legales entre dos bloques opuestos 8. Discusión y conclusiones

Traducido por Paula González (Universidad Católica Andrés Bello, Venezuela)

\section{Introducción}

\subsection{Comienzo del fenómeno social}

En la mañana del 5 de diciembre de 2018, se dio a conocer la noticia de la confirmación de una de las sentencias judiciales más controvertidas de la historia de España, sobre un caso de violencia sexual que había recibido gran atención mediática, conocido como el caso "La Manada". Todos los grandes diarios españoles se hicieron eco de la sentencia en sus portadas y en sus secciones nacionales, destacando que la sentencia hablaba de 'abuso sexual' y no de agresión sexual o violación: "El TSJN confirma los abusos y no agresión de La Manada" (Ojer, 2018); "El Tribunal Superior de Navarra confirma la condena de La Manada a nueve años de prisión por abuso sexual" (Doria, Álvarez \& Valdés, 2018); "La Justicia navarra confirma la pena de nueve años por abuso sexual a los integrantes de La Manada” (Ortiz \& Álvarez, 2018); “'La Manada': la confirmación de la sentencia vuelve a desatar la indignación" (El Periódico, 2018); "El Tribunal Superior de Navarra mantiene la sentencia por 'La Manada': no hubo violación" (Cedeira, 2018); "Nuevas manifestaciones contra la 'justicia patriarcal' tras la sentencia de 'La Manada' insistiendo en que "no es abuso, es violación"”' (Remacha, 2018).

En cuestión de horas, miles de manifestantes se habían movilizado en toda España, convocados a través de las redes sociales por diferentes grupos, para protestar contra la sentencia del Tribunal 
Superior de Justicia de Navarra (en adelante TSJN) confirmando la condena por abuso sexual en lugar del delito más grave de violación. El incidente se había producido el 7 de julio de 2016, a las 2:50 horas, en el centro de la ciudad de Pamplona durante las fiestas de San Fermín, una de las fiestas más populares y conocidas de España. La víctima, que presentó cargos por violación, era una mujer de 18 años, mientras que los agresores eran cinco hombres que se referían a sí mismos colectivamente como "La Manada" en un grupo de WhatsApp.

El caso llamó la atención de los medios de comunicación de inmediato por varios motivos: en primer lugar, por las imágenes filmadas por los propios agresores, que compartieron en un grupo de WhatsApp, resultando en la "pornificación" de la agresión (Herrera \& Agoff, 2018); y en segundo lugar, dos de los hombres implicados en la violación pertenecían a las fuerzas armadas nacionalesuno a la Guardia Civil y otro a la Unidad de Emergencias Militares. Pero el elemento más impactante de todos fue el hecho de que la defensa de los agresores se organizó en torno a dos argumentos: que la víctima había dado su consentimiento y que era una mujer de dudosa credibilidad. Para obtener evidencia que agrediera el carácter de la víctima, los agresores contrataron a un detective privado para que rastreara su actividad en las redes sociales en los días posteriores a la imputación de cargos.

El fallo se anunció el 26 de abril de 2018. Los cinco hombres fueron condenados a nueve años de prisión por abuso sexual continuo, pero no por violación. Además, los jueces no pudieron llegar a una decisión unánime, ya que uno de ellos se pronunció a favor de la absolución, alegando contra la existencia de conductas constitutivas de delito sexual. El fallo provocó una ola de solidaridad con la víctima, con consignas como "Hermana, te creo", "No te preocupes, hermana, tu manada está aquí" y "No es abuso; es violación", mientras miles de personas salieron a las calles en ciudades de toda España esa misma tarde. Ocho meses después, el 5 de diciembre, la TSJN confirmó la sentencia original de abuso sexual. Nuestra investigación estudia el impacto de esta decisión judicial en Twitter, donde se volvió viral con el hashtag "\#LaManada".

\subsection{Cuestiones teóricas: movilización feminista y violencia sexual}

Los estudios sobre la influencia de las redes sociales en la opinión pública son numerosos. Para esta investigación, los enfocados a confirmar las redes como ecos de resonancia (Klinger \& Svensson, 2014, 2016) o, por el contrario, como filtros de burbujas (Pariser, 2011; Barker, 2018; Bechmann \& Nielbo, 2018; Haim, Graefe \& Brosius, 2018; Puschmann, 2019; Kanai \& McGrane, 2020), fueron especialmente útiles. Por un lado, las redes sociales han viralizado temas y noticias que no tenían visibilidad en los medios de comunicación. Por otro, se han convertido en burbujas de información para algunos sectores de la audiencia, que se desconectan de la actualidad mediática por el feed de sus redes sociales. Este feed se convierte en su única ventana al mundo e incluye muchas y peligrosas noticias falsas (Levi, 2019). Estas dos posiciones opuestas son fundamentales para abordar el objeto de estudio con la mayor objetividad, asumiendo opiniones contrarias sobre los efectos y funciones de las redes sociales.

Los movimientos feministas han demostrado una extraordinaria capacidad de movilización de masas (Melo, 2016; Ana, 2017; Sinha, 2018; Dehesa, 2019; Fernández-Romero, 2019). Ningún partido político, sindicato u organización ha conseguido sacar a la calle a miles de personas como ocurrió, por ejemplo, el 8 de marzo de 2018, cuando más de cinco millones de mujeres participaron en la Huelga de Mujeres en España, y, solamente en Madrid, más de medio millón mujeres se manifestaron (Bernárdez \& Padilla, 2019; Campillo, 2019). La movilización política y el feminismo han sido objeto de diversos estudios en los últimos años, que han vinculado su éxito al uso generalizado de las redes sociales (Aune \& Holyoak, 2017; Scarborough, 2018; Arbatskaya, 2019; 
Barrientos, Caldevilla \& Vargas, 2019; Cabezuelo y Manfredi, 2019; Castillo, Díaz y Caldevilla, 2019; Gorina y Agadjanian, 2019; Gülel, 2019; Rone, 2019).

En el mundo actual, el éxito de cualquier movimiento global, incluido el feminismo, debe entenderse como una interacción entre lo global y lo local, entre redes sociales virtuales y procesos de interacción individual y grupal (Cole, 2015; Baer, 2016; Caldevilla, Rodríguez y Barrientos, 2019; Caldevilla y García, 2020). Los movimientos feministas vienen mapeando su trayectoria activista en un contexto general de transformación de las formas de protesta pública y esfuerzos de diferentes grupos y colectivos para lograr una mayor visibilidad (Bernárdez \& Serrano, 2018; Cooke, 2019; Hatch, 2019; Kamenou, 2019; Savory, 2019; Soysa y Zipp, 2019).

La historia reciente del activismo feminista se ha relacionado con las nuevas formas de protesta que surgieron de las protestas de Seattle de 1999, cuando los llamados "movimientos antiglobalización" aparecieron para subsumir las demandas de pacifistas, feministas, colectivos queer y otros grupos (Marchand, 2014; Moreno y Bernárdez, 2017). Al mismo tiempo, desde la Conferencia Mundial sobre la Mujer en Beijing en 1995, el feminismo institucional ha contribuido a la consolidación del movimiento, bajo la atenta mirada de muchas feministas preocupadas de que esto pueda resultar en la promoción del neoliberalismo y el conservadurismo. En cualquier caso, las cosas cambiaron luego de la crisis financiera de 2008, con el surgimiento de nuevos grupos feministas de acción directa como Femen y la consolidación de un feminismo académico activo (Bermudez \& Johnson, 2018; Bernárdez \& Padilla, 2018) que ha ido educando a miles de mujeres y hombres jóvenes.

En este contexto, los movimientos feministas han experimentado una evolución en todo el mundo gracias a la existencia de las redes sociales digitales. Como ha sido el caso de otros grupos ciudadanos, movimientos sociales, organizaciones e instituciones, gracias a Internet estas comunidades pueden compartir información, ofrecerse apoyo mutuo, organizar, movilizar y/o consolidar identidades colectivas (Bastos \& Mercea, 2015; Fan, Wu, Wall y Zhou, 2019; Hsu, 2019; Lin y Yang, 2019; Phillips y Yi, 2019). Ya no dependen exclusivamente del megáfono de los medios convencionales para hacer llegar sus mensajes a audiencias masivas (Brennan, 2018; Gray-Hawkins, 2018; Lăzăroiu, 2018; Anguí, Cabezuelo \& Sotelo, 2019; Hasunuma \& Shin, 2019). Hoy, gracias a Internet, las redes sociales digitales y la tecnología móvil, sus ideas pueden traspasar barreras y fronteras a bajo costo y, lo que es más importante; pueden invertir la construcción de arriba hacia abajo de la opinión pública y de la agenda pública (Jivkova, Requeijo \& Padilla, 2017; Padilla \& Oliver, 2018; Bernárdez, Padilla \& Sosa, 2019).

Sin embargo, si bien su importancia es innegable, el éxito de los movimientos feministas en el mundo no puede atribuirse únicamente al efecto de las redes sociales digitales. Las manifestaciones callejeras han jugado un papel fundamental desde al menos 2012. Países como India, Argentina, Polonia y Estados Unidos (Movimiento \#MeToo, Marcha de Mujeres contra Trump) han visto protestas masivas contra todo tipo de violencia (no solo física o sexual) contra las mujeres. Por ejemplo, las movilizaciones de "El tren de la libertad" en España, en protesta contra la propuesta del gobierno conservador de cambiar la ley sobre el aborto en 2014, fueron extremadamente importantes. Desde entonces, el número de asociaciones feministas de todo tipo ha ido aumentando de forma constante (Etura, Martín \& Ballesteros, 2019; Gallur \& García, 2019; De-Miguel, Parratt \& Berganza, 2019; Mojica, Espinel \& Botero, 2019; Seperak et al., 2019).

El movimiento feminista de todo el mundo se ha unido en torno al tema de la violencia sexual como un problema común que afecta a las mujeres en todas las culturas y en cualquier momento de la historia. El feminismo académico ha identificado la importancia de cómo se discute públicamente la violencia sexual y la necesidad de dar voz a aquellas mujeres que, precisamente por el trauma que 
han sufrido, no pueden hablar de su experiencia. Además, las nuevas redes sociales brindan una nueva forma de generar una "conversación social" (Armstrong \& Mahone, 2017; Mendes, Keller \& Ringrose, 2018; Fontenla, Rúas \& Conde, 2020; Galletero, López \& Martínez, 2020; Ruiz \& Bustos, 2020), donde las mujeres pueden encontrar espacios anónimos seguros para compartir sus experiencias, al mismo tiempo que se tiene en cuenta que vivimos en sociedades donde existe una cultura de violación (Williams, Christopher \& Sinski, 2017; Worsley et al., 2017; StubbsRichardson, Rader \& Cosby, 2018) que también se difunde en las redes sociales.

El caso de "La Manada" en España es muy significativo porque revela hasta qué punto la violencia sexual sirve al sistema patriarcal. Orbegozo, Morales y Larrondo (2019) estudiaron la conversación digital en Twitter que generó la sentencia, separando los comentarios espontáneos y emocionales de los más reflexivos e ideológicos. Núñez-Puente y Fernández-Romero (2019) investigaron la construcción discursiva de los hashtags \#YoSiTeCreo y \#YoNoTeCreo, como una respuesta política que generó comunidades feministas afectivas de Resistencia. Además, Molpeceres y Filardo-Llamas (2020) utilizaron retórica constructivista y análisis del discurso para analizar 100 tuits que generaron conversaciones en Twitter, utilizando el hashtag \#laManada. En algunos casos, la violencia sexual se considera aborrecible en el cuerpo social, pero en el otro, está presente a nivel simbólico, representando la dominación masculina. Específicamente, los casos de violación grupal tienden a entenderse como incidentes aislados provocados por hombres que de alguna manera han sido "tentados" por mujeres que han ingresado a espacios públicos donde no pertenecen. La violación en sí es un acto de exhibición del poder masculino, incluso ensalzado en el arte tradicional en imágenes del "rapto" de las mujeres por los dioses (Berber, 2017; Bernárdez \& Moreno, 2017; Pradhan, 2019; Tapia y Del-Toro, 2019; Martínez, Alcalde y Santamaría, 2020).

La violación en grupo refleja un patrón de exhibición de poder sobre el cuerpo de la mujer que se hace evidente hoy en la grabación y circulación de videos e imágenes de agresión en las redes sociales (Harp, Grimm \& Loke, 2018). Estas imágenes pasan a formar parte de la pornificación de las agresiones sexuales (Mendes, Keller \& Ringrose, 2018), que parecen adquirir su mayor poder cuando se muestran en entornos grupales masculinos. La tolerancia a este tipo de actos, la negativa a creer el testimonio de las mujeres y exonerar a los hombres que basan su defensa en los "límites difusos" del consentimiento sexual (Cense, Bay-Cheng \& van Dijk, 2018) es un ejemplo de cómo el patriarcado, en un momento histórico de la consecución de los derechos de las mujeres, está reafirmando su poder por la fuerza. Esto también lo demuestran las importantes dificultades que parece tener el aparato legislativo para aceptar el testimonio de las mujeres (McGlynn, 2017, Harper, Franco \& Wills, 2019).

En España, este tipo de violación era efectivamente invisible hasta hace muy poco tiempo porque, como se desprende del informe elaborado por el proyecto Geoviolencia Sexual de España 2016-2018 (Atencio, 2018), no existe una cultura de denunciar la violencia sexual, no existen indicadores para medir sus múltiples variedades, y una perspectiva feminista está ausente en la respuesta pública a los casos, que son demasiado comunes. En 2015 se realizó en España una macroencuesta, elaborada por la Oficina del Gobierno para la Violencia de Género, que reveló que el 7,2\% de las mujeres (1,7 millones) habían sufrido alguna forma de agresión sexual en su vida. Según el Informe Trimestral sobre Delitos publicado por el Ministerio del Interior (2018), en los primeros cuatro meses de 2018 se denunciaron un promedio de cuatro violaciones por día.

Una estrategia para encubrir la violencia sexual en nuestras sociedades es tratarla como un efecto de la guerra o situaciones de extrema pobreza o como producto de "otras culturas patriarcales", trasladando la preocupación a territorios imaginarios con circunstancias excepcionales (Kirby, 2015). En cualquier caso, la violencia sexual se visualiza como un problema que puede resolverse mediante 
severas medidas políticas o judiciales (Quilter, 2016; Amnistía Internacional, 2018a), sin reconocer que refleja un sistema patriarcal en el que el poder masculino se exhibe sin arrepentimientos en la ficción y se restringe solo parcialmente en la realidad.

El Convenio del Consejo de Europa sobre Prevención y Lucha contra la Violencia contra las Mujeres y la Violencia Doméstica, más conocido como el Convenio de Estambul, es un punto de inflexión en relación con esta actitud permisiva. Presentado en la capital turca en 2011, entró en vigor en la Unión Europea el 1 de agosto de 2014. Hasta la fecha es "el tratado internacional más amplio" en la lucha contra la violencia contra las mujeres y la violencia doméstica. Incluso en su preámbulo, reconoce la naturaleza estructural de la violencia contra la mujer como un mecanismo social de sumisión por parte de los hombres que se ha perpetuado a través de una cultura de tolerancia y negación, y reconoce cualquier forma de violencia-desde el acoso sexual hasta la violación, incluyendo los matrimonios forzados, los llamados delitos de "honor", mutilación genital y violencia domésticacomo una "grave violación de los derechos humanos de mujeres y niñas y un gran obstáculo para el logro de la igualdad" (CETS, 2011).

Uno de los elementos más innovadores de la convención está contenido en el Artículo 36, relacionado con la violencia sexual y la violación. Por primera vez aparece la palabra "consentimiento" con respecto a las relaciones sexuales. El artículo enfatiza que el consentimiento "debe darse voluntariamente como resultado de la libre voluntad de la persona evaluado en el contexto de las circunstancias circundantes" (CETS, 2011) y enfatiza que los Estados signatarios deben tomar las medidas judiciales, o de otro tipo, necesarias para asegurar la tipificación como delito de cualquier conducta fuera de este contexto de consentimiento expreso.

A pesar de su importancia, solo ocho países europeos han adaptado su legislación al Convenio de Estambul: Reino Unido, Irlanda, Luxemburgo, Alemania, Chipre, Bélgica, Islandia y Suecia. En España, la primera sentencia sobre el caso "La Manada" encendió un debate sobre la necesidad de cambiar el Código Penal (Amnistía Internacional, 2018b), y en diciembre de 2018, un grupo de expertos que trabaja en esta reforma propuso al Ministerio de Justicia la eliminación del delito de abuso sexual para que todos los delitos sexuales se clasifiquen como agresión o violación.

\section{Objetivos}

El objetivo principal de esta investigación es analizar los flujos de interacción registrados en la red social Twitter que pueden haber fomentado la movilización social contra un poder de gobierno (el judicial) que pocas veces ha sido blanco de una protesta callejera tan masiva, e identificar las principales voces de estos flujos de comunicación. Este objetivo principal contiene estos objetivos secundarios:

1. Conocer la naturaleza de los tweets más influyentes, si son originales o si un retweet puede tener más visibilidad que a la que se refiere el tweet original;

2. Reconocer los días y horas en que se publicaron tweets y retweets más notorios;

3. Conocer el número de seguidores anteriores de los usuarios con más notoriedad, saber si este número es importante para ganar notoriedad;

4. Percibir la posible relación entre usuarios, tweets y retweets;

5. Detectar qué usuarios eran medios de comunicación o figuras públicas;

6. Y especialmente, como elemento original respecto a las investigaciones previas sobre Twitter y el caso "La Manada", para detectar si entre los usuarios más notorios hay voces legales autorizadas o peritos legales que emitieron opiniones a favor o en contra de la sentencia judicial, lo que podría generar opinión pública en el resto de usuarios de la red. 
Nuestro estudio toma como hipótesis de partida las siguientes:

1. La naturaleza de la comunicación en Twitter no es horizontal como se supone generalmente, sino que está condicionada por ciertos individuos e instituciones, como periodistas, medios de comunicación, líderes y partidos políticos y celebridades, quienes son los verdaderos líderes de opinión que marcan las tendencias en opinión pública.

2. A pesar de lo anterior, las redes sociales ofrecen un espacio para voces alternativas que pueden tener más influencia que los líderes políticos y mediáticos tradicionales.

3. El éxito de las protestas callejeras se explica no solo por la rápida y eficaz circulación de la noticia del fallo en las redes sociales y de los hashtags que lo difundieron, sino también por la existencia de tantos colectivos y agentes sociales con el poder de llevar gente a la calle.

4. La agresión sexual y la violación, en particular, se han convertido en una preocupación clave en la agenda feminista española en los últimos años.

Esta investigación se enmarca dentro del Proyecto I+D+i, Programa Excelencia, Subprograma Estatal de generación de conocimiento, titulado Producción Cultural en redes sociales: industria, consumo popular y alfabetización audiovisual de la juventud española con perspectiva de género (2018-2022), otorgado por el Ministerio de Economía, Industria y Competitividad con la referencia FEM2017-83302-C3-3-P.

\section{Cuestiones metodológicas}

La metodología utilizada es de naturaleza cuantitativa, aunque también se introducen evaluaciones cualitativas del contenido del mensaje. En primer lugar, para analizar el impacto en Twitter de la decisión del Tribunal Superior de Justicia de Navarra de mantener la sentencia de abuso sexual para los cinco integrantes de "La Manada", utilizamos la plataforma T-hoarder_kit (Congosto et al., 2017) para recopilar los tweets publicados entre las 7:54 am y las 11:54 pm el 5 de diciembre con el hashtag "\#LaManada". Este hashtag se volvió viral rápidamente en esta fecha, como lo demuestran los 73.904 tweets capturados a través de la interfaz de programación de aplicaciones de transmisión (API) de Twitter.

La plataforma T-hoarder permite almacenar tweets sobre temas de interés en las redes sociales. Líneas temáticas en tres ejes dividen este almacenamiento: temporal, espacial y relevante (Congosto, 2017). El eje temporal indica la proporción de mensajes transmitidos en el período elegido, los usuarios más activos o más mencionados, los hashtags más utilizados o las palabras más frecuentes. El eje espacial ubica los tweets geográficamente. Además, el eje de relevancia destaca los tweets que obtienen más notoriedad en cada área (Congosto, 2017).

Estos tres ejes tienen una arquitectura simple en tres capas: recolección y almacenamiento de datos, procesamiento de datos y visualización (Congosto, 2017). Los componentes de cada capa están programados en Python, un lenguaje de programación propiedad de la Python Software Foundation, con licencia de código abierto y gratuito para cualquier usuario. Actualmente, Python ofrece su versión 3.8.3, desde marzo de 2020. Sin embargo, T-hoarder es compatible con Python 2.7 .12 o superior siempre que sea 2.7 .

La selección de tweets a través de T-hoarder comienza con la aplicación Tweetdeck, que interactúa con la API de Twitter, para que los usuarios puedan conectar múltiples cuentas de Twitter, hacer una cronología común en la misma interfaz, programar la publicación de tweets y crear colecciones de tweets, como en el caso de esta investigación. Específicamente, T-hoarder usa la API de transmisión para filtrar usando palabras clave, usuarios o geolocalización. Después de elegir uno de los tres 
filtros, la API de transmisión proporciona los tweets en formato JSON, un formato de texto simple y legible para casi todos los programas de procesamiento de texto.

De toda la información recibida, se seleccionan los datos que son útiles para analizar el tuit: identificador, fecha y hora GMT del tuit, nombre del usuario que es el autor del tuit, texto del tuit, aplicación desde la que el tuit fue publicado, identificador del autor, número de seguidores en el momento de la publicación, número de usuarios seguidos en el momento de la publicación, número de tweets publicados anteriormente, ubicación declarada en el perfil del usuario, enlace si el tweet contiene una URL, coordenadas si el tweet está geolocalizado, nombre proporcionado por el usuario, descripción del usuario, URL si el tweet contiene información multimedia, tipo de información multimedia e idioma del tweet (Congosto, 2017). T-hoarder elige los tweets por su relevancia en forma de retweets. No cuenta los retweets de la API de Twitter por tratarse de datos dinámicos en el tiempo, mientras que la API de transmisión permite detectar retweets automáticos y manuales (Congosto, 2017).

Los resultados del análisis fueron transformados en gráficos, por los autores, con el software Tableau. Este programa de creación de gráficos ofrece un procesamiento de datos intuitivo centrado en la velocidad normal de la comprensión visual humana. Tableau es compatible con cualquier sistema de almacenamiento de datos y ofrece su interfaz en inglés, francés, alemán, español, portugués, japonés, coreano y chino. Es compatible con los sistemas operativos Windows 7 o posterior y OSX 10.11 o posterior (Tableau.com, 2020).

Se utilizó Gephi para analizar las relaciones y dinámicas declaradas entre usuarios generadas como resultado de los retuits recopilados. Esto ayudó a visualizar las comunidades más poderosas y la fuerza de los lazos que conectan a sus usuarios. Gephi es un software gratuito. Es compatible con Windows, Mac OS X y Linux. Para esta investigación, se utilizó la última versión disponible, Gephi 0.9.2. Para la mejor visualización de los resultados, dentro de las herramientas que ofrece Gephi, se eligió el mapeo que permite la personalización de los nodos mediante colores, tamaños y etiquetas (Gephi.org, 2020). Los nodos corresponden a los nombres de los usuarios que obtuvieron la mayor notoriedad. El tamaño de su nombre en la cartografía corresponde a su mayor o menor importancia. Además, a cada uno se le asignó un color diferente que permitía visualizar interacciones o uniones.

Finalmente, aplicamos el análisis de contenido a los mensajes más retuiteados como una forma de explorar las reacciones de los usuarios a la decisión del TSJN.

\section{Resultados}

Obtuvimos un total de 73,904 tweets capturados a través de la interfaz de programación de aplicaciones de transmisión (API) de Twitter: 49,886 (67.5\%) fueron retweets, es decir, contenido reenviado basado en mensajes originalmente publicados por otros usuarios, mientras que el otro $32.5 \%$ fueron mensajes originales con o sin menciones a otros usuarios y respuestas a otros tweets, como se ve en la Figura 1 a continuación. 


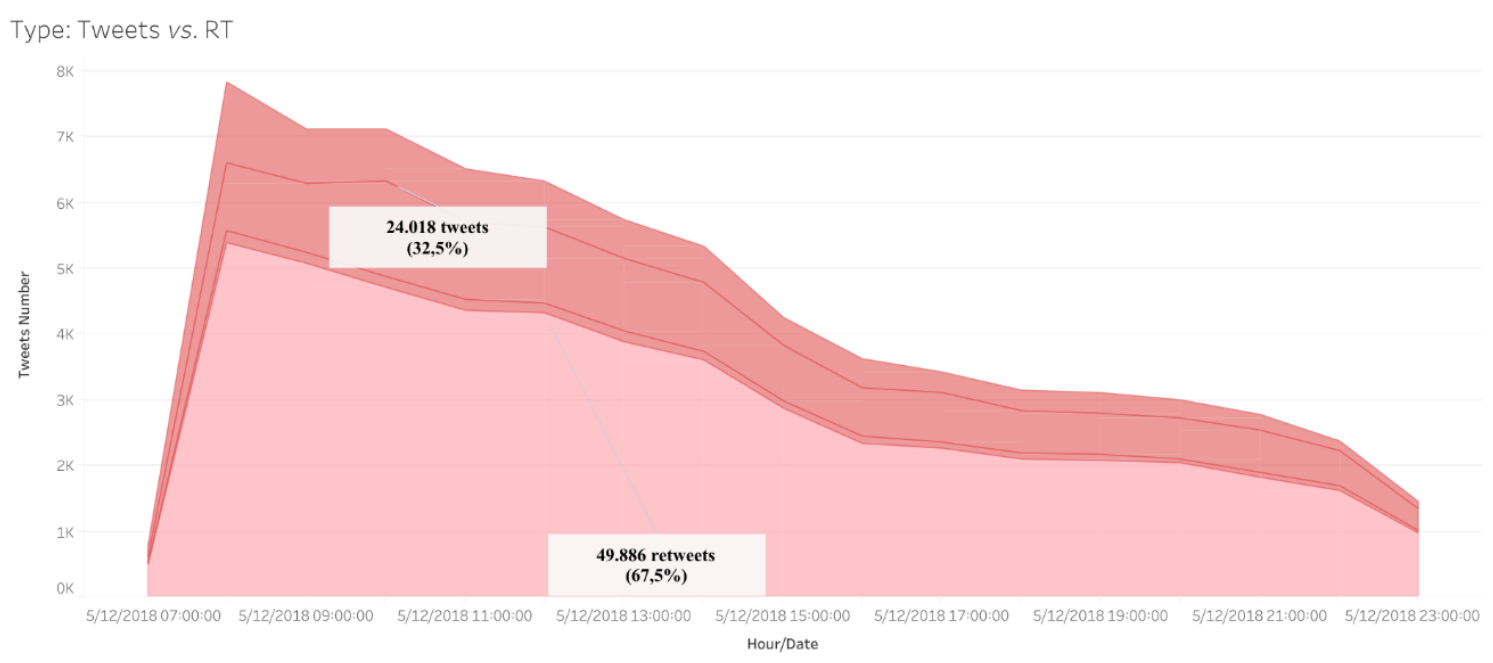

Figura 1: Tweets “originales" vs. retweets.

Fuente: Elaboración propia.

Dado que las redes sociales son plataformas de comunicación muy recientes cuyo desarrollo está sujeto a constantes cambios debido, entre otros factores, a normativas legales y modificaciones algorítmicas diseñadas para garantizar la seguridad del usuario y frenar las amenazas detectadas en el uso de la tecnología, no existe una metodología global consolidada para el análisis de datos, o para ayudar a los investigadores de redes sociales a procesar los enormes volúmenes de información actualmente disponible (Congosto, 2018, p. 3, 16). Sin embargo, dado que los retweets representan dos tercios del número total de tweets capturados y el análisis de los flujos de interacción en Twitter ha demostrado que lo que no se viraliza no tiene un impacto real, en este caso de estudio limitamos nuestra investigación a los diez usuarios cuyos mensajes fueron retuiteados más de 500 veces, como se muestra en la Figura 2 a continuación.

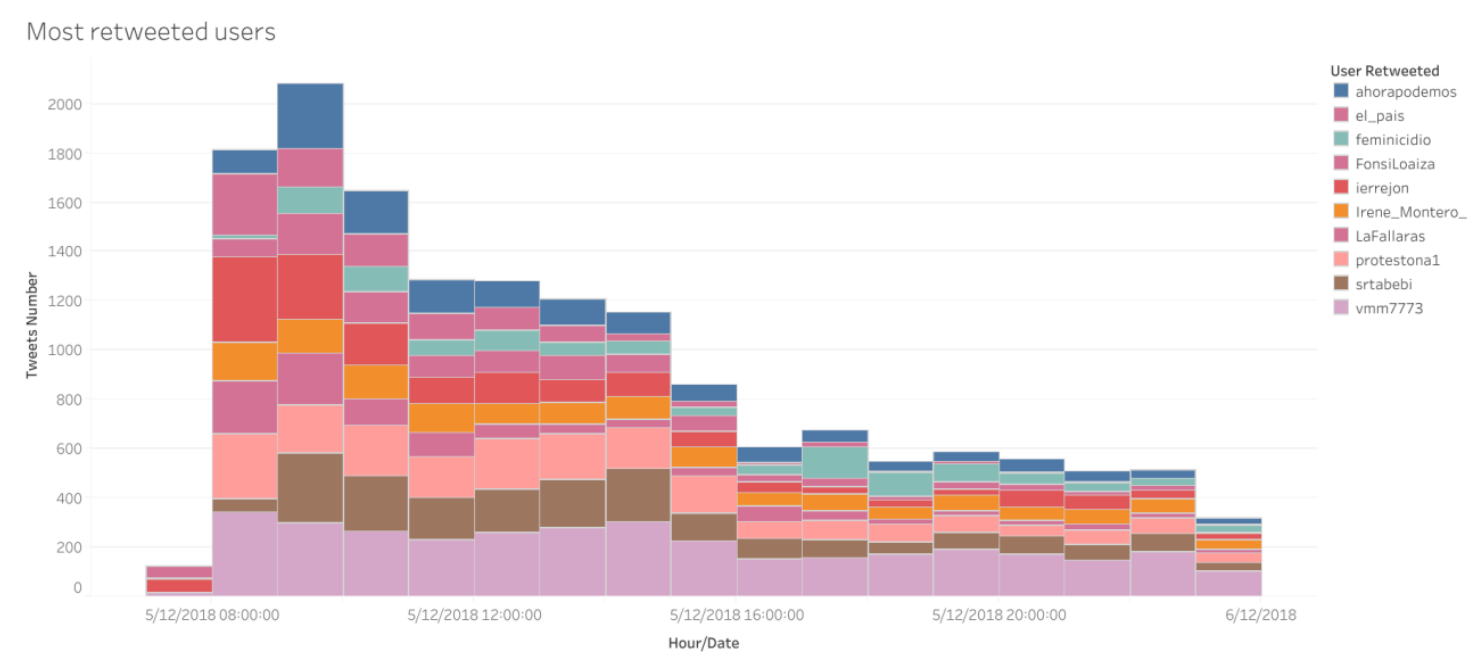

Figura 2: Usuarios más retuiteados.

Fuente: Elaboración propia.

La difusión del hashtag \#LaManada durante el transcurso del 5 de diciembre de 2018 refleja el hecho de que la distribución de tweets está asociada con momentos de intensidad y "trauma colectivo", como se ve en la Figura 3 a continuación. 


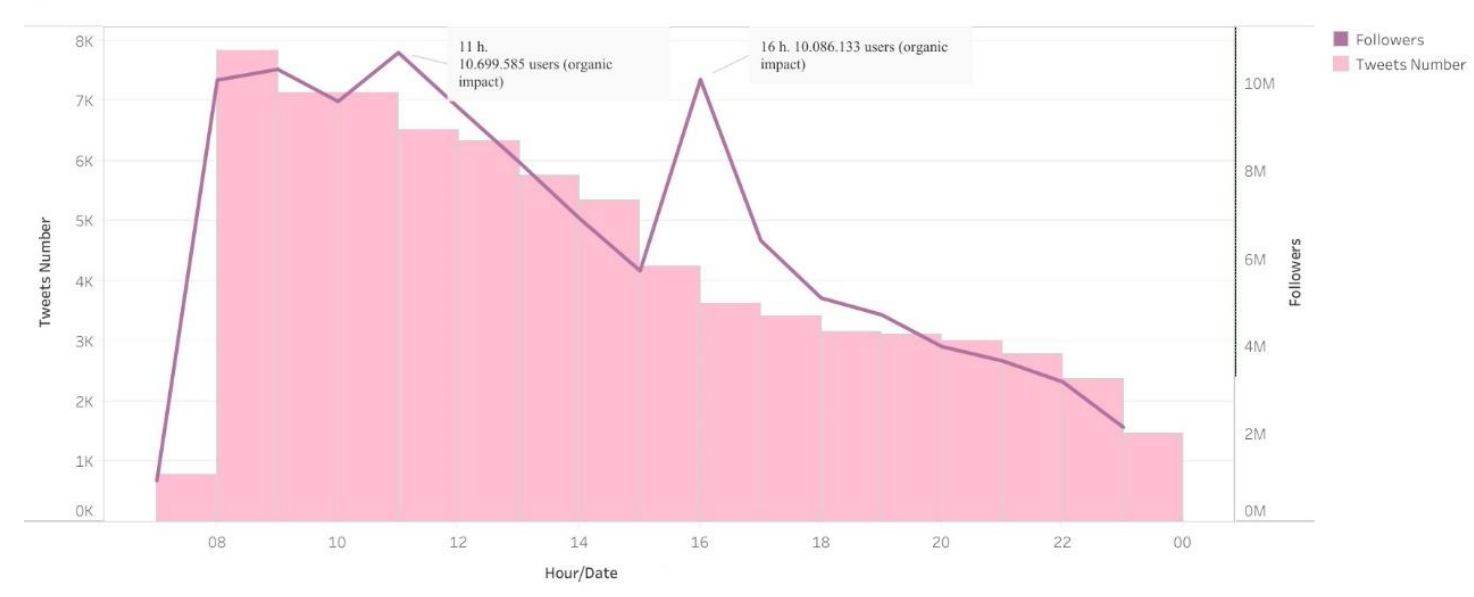

Figura 3: Difusión del hashtag “\#LaManada”.

Fuente: Elaboración propia.

Esta característica, unida a un modelo de comunicación caracterizado por la inmediatez, la actualización constante de contenidos y la publicación de mensajes concisos marcados por la emoción, hacen de Twitter el canal por excelencia para expresar la indignación social.

La noticia del fallo del TSJN apareció por primera vez en la red social en la madrugada cuando, a las 4:44 a.m., el diario El País la tuiteó con la leyenda "última hora". Este tweet recibió 497 retweets en dieciséis horas. Sin embargo, como muestra el histograma asimétrico de la derecha que mide la difusión del hashtag, el mayor impacto en la red social se produjo después de las 8 a.m., cuando la mayoría de los usuarios se conectan a Twitter. A estas alturas, muchos medios de comunicación españoles e internacionales ya habían publicado la noticia, y la red social empezó a hervir con comentarios relacionados con el caso.

Entre las 8 y las 9 a.m. se registraron un total de 7.826 tweets, y la cifra horaria disminuyó progresivamente a medida que avanzaba el día. En términos de la cantidad de usuarios potenciales que vieron estos tweets, se pueden observar dos picos: uno, alrededor de las 11 a.m., de 10,6 millones de usuarios; y el otro, a las 4 p.m., de 10 millones.

\section{Usuarios más retuiteados}

Un análisis de contenido de los mensajes publicados por los diez usuarios más retuiteados, revela la reacción negativa a la decisión del Tribunal Superior de Justicia de Navarra. Un tercio de los retweets contienen objeciones al fallo, constituyendo una gran comunidad que, como se puede apreciar a continuación en el gráfico de modularidad, es claramente feminista y crítica tanto con la decisión judicial como con el Código Penal, como se observa en la Tabla 1 a continuación.

Tabla 1. Características de los usuarios más retuiteados.

\begin{tabular}{|l|l|l|l|l|l|l|}
\hline & & & & \multicolumn{1}{|l|}{ RTs } \\
\hline Usuarios & Actividad Declarada & Siguiendo & Seguidores & Tweets & $\begin{array}{l}\text { Frecuencias } \\
\text { Absolutas }\end{array}$ & $\begin{array}{l}\text { \% } \\
\text { @ vmm7773 }\end{array}$ \\
$\begin{array}{l}\text { Perra Roja De Satán. Odiando el } \\
\text { fascismo desde 1977. Colaboradora de } \\
\text { @Diario_16 }\end{array}$ & 77.495 & 113.776 & 6 & 3.476 \\
\hline
\end{tabular}


RLCS, Revista Latina de Comunicación Social, 79, 237-262

[Investigación] DOI: 10.4185/RLCS-2021-1502| ISSN 1138-5820| Año 2021

\begin{tabular}{|c|c|c|c|c|c|c|}
\hline$@$ @ protestona1 & $\begin{array}{l}\text { Republicana, feminista, atea y roja. } \\
\text { Con Podemos }\end{array}$ & 2.182 & 152.824 & 5 & 2.249 & $5 \%$ \\
\hline$@$ srtabebi & Bebi Fernández. Escritora y feminista & 372 & 607.467 & 2 & 2.155 & $4 \%$ \\
\hline @ierrejon & $\begin{array}{l}\text { Secretaria de Análisis Estratégico y } \\
\text { Cambio Político y congresista de } \\
\text { Unidos Podemos }\end{array}$ & 2.204 & 827.850 & 1 & 1.635 & $3 \%$ \\
\hline @ahorapodemos & Partido político & 1.548 & 1.349 .456 & 2 & 1.398 & $3 \%$ \\
\hline @lafallaras & Periodista y escritora & 5.027 & 101.624 & 3 & 1.346 & $3 \%$ \\
\hline @irene_montero_ & $\begin{array}{l}\text { Psicóloga, madre, feminista, por una } \\
\text { vivienda digna. Portavoz de Unidos } \\
\text { Podemos en el Congreso }\end{array}$ & 1.873 & 272.256 & 1 & 1.346 & $3 \%$ \\
\hline$@$ feminicidio & $\begin{array}{l}\text { Noticias con perspectiva feminista, } \\
\text { cursos online y base de datos sobre } \\
\text { feminicidios en España }\end{array}$ & 3.165 & 74.034 & 12 & 1.005 & $2 \%$ \\
\hline @ fonsiloaiza & \begin{tabular}{lcc} 
Cantero del clic. & Doctora en \\
Periodismo. & Por un deporte \\
democrático: & \multicolumn{3}{c}{ antifascista, } \\
anticapitalista y feminista
\end{tabular} & 640 & 73.859 & 2 & 951 & $2 \%$ \\
\hline @el_pais & Periódico & 761 & 6.792 .880 & 3 & 777 & $2 \%$ \\
\hline
\end{tabular}

Fuente: Elaboración propia.

En un análisis más detallado, se encontró que los diez usuarios más retuiteados incluían líderes políticos, activistas feministas, periodistas y dos medios de comunicación: una fuente de noticias generales de los medios de comunicación (el periódico El País); y un sitio web de noticias desde una perspectiva feminista (feminicidio.net), que publica un informe mensual sobre el número de mujeres víctimas de violencia de género en España y ofrece información sobre otras cuestiones relacionadas con los derechos, intereses y causas de las mujeres. En todos los casos, estos usuarios son influencers importantes con más de 70.000 seguidores (hasta 6,7 millones en el caso de El País, lo que no es de extrañar dado que es uno de los periódicos más importantes de España).

La posición de la cuenta de Twitter de El País entre los diez nodos más importantes en el flujo de retweets se debe a que fue el primer medio en publicar la noticia y la fuente desde la que comenzó a difundirse el tema en la red. Sin embargo, su influencia en el conjunto de los retweets es insignificante: apenas un $2 \%$.

La influencia de escritoras y periodistas abiertamente feministas fue bastante más significativa. La persona que se esconde detrás del seudónimo "Perra Roja de Satán”(@vmm7773), que se autoidentifica como mujer y como colaboradora ocasional del portal de noticias Diario 16, fue responsable del 7\% de los retweets con 6 microposts. Este usuario, la escritora Bebi Fernández (@ srtabebi), y los periodistas Cristina Fallarás y Fonsi Loaiza representan el 16\% del total. Es interesante notar que el sitio web feminicidio.net fue el usuario más activo, ya que publicó 12 tweets que fueron retuiteados más de 1,000 veces. Todos estos representan el $18 \%$ de los retweets de los diez usuarios más retuiteados (8,933 veces).

Tras estos usuarios, la comunidad más poderosa es la política, formada por la coalición de izquierda Ahora Podemos (que agrupa a los partidos Podemos e Izquierda Unida), dos de sus líderes (los congresistas Irene Montero e Íñigo Errejón), y la cuenta de Twitter @ protestona1, seudónimo de una usuaria que se identifica como simpatizante de Podemos. Estos tres representan el $11 \%$ del total de retweets analizados. El poder de esta comunidad que se opone a la decisión del tribunal de mantener la sentencia de abuso sexual y no agresión para los cinco integrantes de "La Manada", también se hace evidente en el análisis de redes sociales que ofrece Gephi, como se observa en el Gráfico 1 a continuación. 


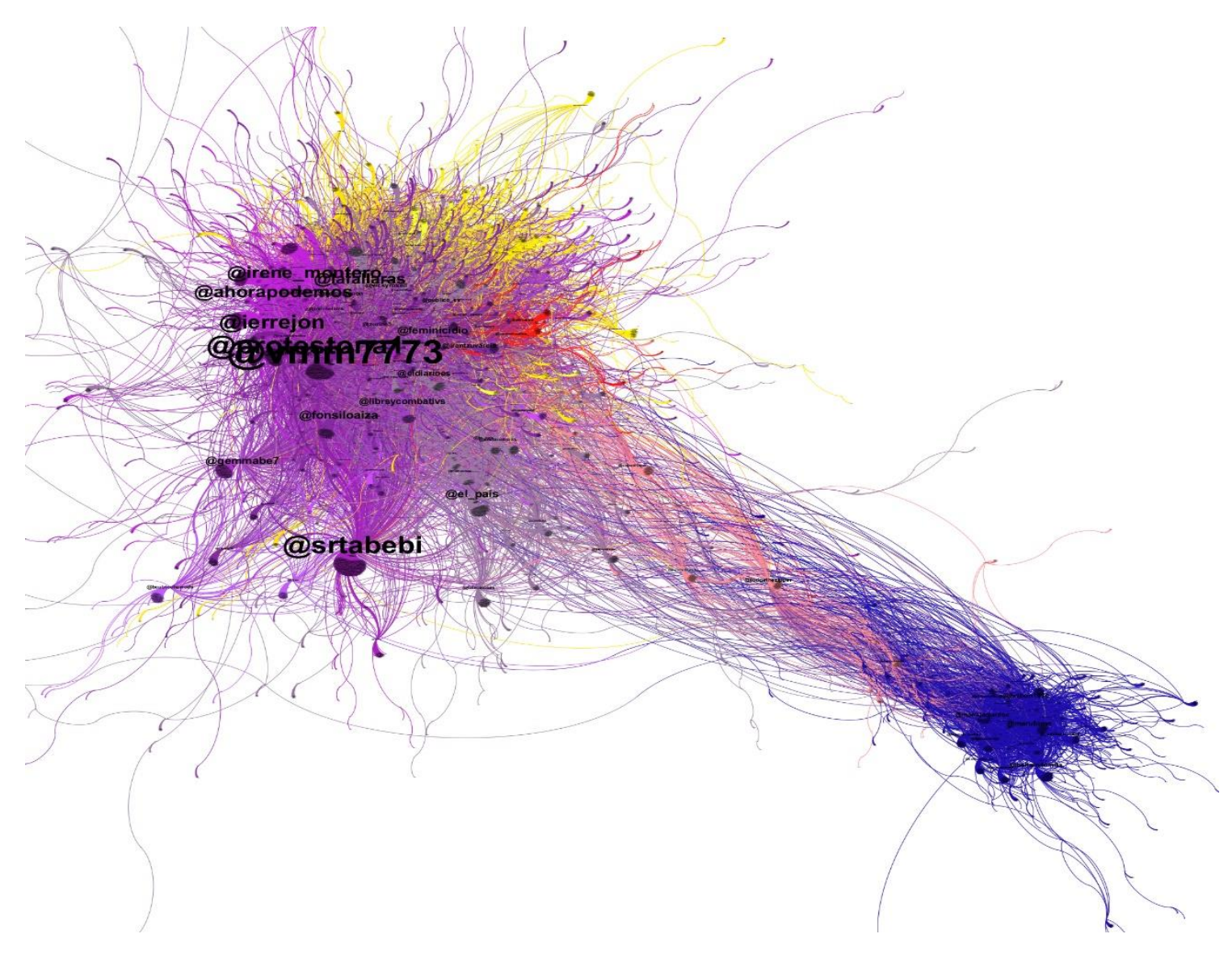

Gráfico 1: Comunidades emergentes en el flujo de retweets.

Fuente: Elaboración propia.

Al aplicar la métrica de modularidad a los datos, los nodos más grandes dentro del flujo de interacción emergen en el gráfico. Su tamaño es directamente proporcional a su grado de centralidad. En otras palabras, los nodos más grandes son aquellos cuyos mensajes fueron retuiteados más y, por lo tanto, atrajeron más enlaces. El resultado es una rotunda oposición al fallo judicial por parte de la mayoría de usuarios. En concreto, de los 32.833 nodos visibles en el gráfico, el 40,6\% pertenecen a perfiles abiertamente feministas que protestan contra la decisión judicial. Liderando esta comunidad están Ahora Podemos, algunos de sus partidarios y algunos colectivos y activistas feministas.

En términos de contenido, la mayor parte de los tuits cuestionan la decisión de los jueces (criticando el hecho de que la sentencia es solo por abuso sexual porque el acusado "no tuvo que usar la fuerza ni la violencia") y denunciando el "sesgo misógino" de un sistema de justicia que describen como "patriarcal". En este sentido, cabe destacar el hecho de que después de "\#LaManada" el segundo hashtag más utilizado en Twitter fue "\#JusticiaPatriarcal".

La idea de una decisión judicial "misógina", "vergonzosa" que "confirma que, si no te matan o golpean hasta dejarte sin sentido, un caso de violación será catalogado como mero abuso sexual" está presente en 21 de los 53 tuits publicados por los diez usuarios más retuiteados. Esta proporción puede parecer baja, ya que representa menos de la mitad de los tuits, pero lo importante aquí es la cantidad de retuits. Estos 21 tweets fueron retuiteados 10,338 veces, lo que significa que la indignación por la decisión del TSJN se expresa en el 20.72\% de los retuits recolectados. 
$\mathrm{Si}$, como casi una cuarta parte de los usuarios de Twitter involucrados en la difusión de este tema en la red social retuitea, la decisión del tribunal fue incorrecta, una posible solución sería cambiar la ley, propuesta que aparece en cuatro tweets $(6,81 \%$ de los retweets). De estos, uno de los más contundentes es un tuit de Ahora Podemos que anuncia: "Vamos a presentar un proyecto de ley que asegure que \# SoloSíEsSí. La misoginia debe ser sacada de los tribunales de justicia”. En su opinión, esto es necesario porque el mensaje que transmite la decisión del TSJN es "impunidad para los violadores"; en resumen, "les está diciendo a las mujeres que, si no patean, si no gritan, si no arriesgan sus vidas, no están siendo violadas". Poco antes de que el Tribunal Superior de Navarra confirmara la condena por abuso sexual de los miembros de "La Manada", la organización internacional Women's Link había catalogado la sentencia entre "las peores sentencias sobre igualdad de género dictadas por tribunales de todo el mundo en el año (2018)". (Europa Press, 2018), hecho destacado por las investigadoras de feminicidio.net, que al mismo tiempo subraya la "urgente necesidad" de políticas públicas para prevenir la violencia sexual.

Sin embargo, a corto plazo, fueron los mensajes que pedían acción y movilización en las calles los que recibieron la mayor respuesta. La conclusión fue que "no podemos quedarnos al margen" porque el poder judicial se "opone" a los intereses y la seguridad de las mujeres, se puede encontrar en 12 tweets. Estos mensajes fueron retuiteados 5.068 veces, lo que representa un 10,16\% de los RT recogidos. A excepción del periodista Fonsi Loaiza y el diario El País, todos los usuarios más retuiteados invocaron el poder de la calle para desafiar lo que calificaron como "justicia patriarcal" y defender "una vida digna, libre de violencia misógina".

En el contenido de los tuits también hay críticas al abogado de los cinco integrantes de "La Manada", por su afirmación de que "hay de todo menos dolor" en el video que filmaron sus clientes de la violación de la joven, mientras que también se condena a los medios de comunicación por dar rienda suelta al abogado. En el repudio generalizado al fallo, algunos de los diez usuarios más retuiteados extendieron sus críticas a dos de los partidos de derecha de España: el Partido Popular (el tradicional partido conservador español), y VOX, acusados de misóginos, especialmente este último. VOX, considerado un partido de extrema derecha, ha hecho de la lucha contra el feminismo (o lo que llama "ideología de género") una de sus principales plataformas, un punto destacado por feminicidio.net, que señala que "el 72\% de los votantes de VOX son hombres. Defienden los privilegios del macho ibérico. Mientras tanto, 50 mujeres son asesinadas y 1.000 mujeres son violadas en nuestro país cada año y 'La Manada' goza de impunidad". Las condenas a VOX y la extrema derecha están presentes en 4 tuits que fueron retuiteados un total de 1.497 veces (3\% de los RT recogidos).

\section{Contraataque}

Uno de los aspectos más interesantes del gráfico es su revelación del surgimiento de un grupo que toma represalias contra los mensajes tuiteados principalmente por los miembros de Ahora Podemos, y en concreto por su portavoz en el Congreso, Irene Montero. Con el 12,11\% de los nodos, el grupo azul del gráfico contiene la mayor cantidad de nodos, aunque no tuvo suficientes seguidores para contrarrestar la reacción abrumadoramente negativa de la comunidad feminista.

Dentro de este grupo, los usuarios más retuiteados representaron el 7,45\% de todos los RT recopilados, publicando once tweets que fueron retuiteados 3.497 veces en la red, como se muestra en la Tabla 2 a continuación. 
RLCS, Revista Latina de Comunicación Social, 79, 237-262

[Investigación] DOI: 10.4185/RLCS-2021-1502| ISSN 1138-5820| Año 2021

Tabla 2: Características de los usuarios más retuiteados en la comunidad anti-Podemos.

\begin{tabular}{|c|c|c|c|c|c|c|}
\hline & & & & & RTs & \\
\hline Usuarios & Actividad Declarada & Siguiendo & Seguidores & Tweets & $\begin{array}{l}\text { Frecuencias } \\
\text { absolutas }\end{array}$ & $\%$ \\
\hline$@$ marubimo & $\begin{array}{l}\text { Madridista hasta la médula. Española } \\
\text { hasta la muerte. No puedo con el } \\
\text { populismo coletero. }\end{array}$ & 20.843 & 34.283 & 1 & 523 & $1 \%$ \\
\hline @bribon 1970 & $\begin{array}{l}\text { Pícaro de extrema derecha. Vivimos } \\
\text { en una sociedad donde los buenos } \\
\text { son ignorados como hormigas y los } \\
\text { malos son adorados como dioses } \\
\text { (Simón Von Fordback) }\end{array}$ & 3.292 & 9.696 & 1 & 495 & $1 \%$ \\
\hline @bellaindomita & $\begin{array}{l}\text { La política me enciende. Me muerdo } \\
\text { el labio porque no puedo morderme } \\
\text { la lengua. Intolerancia a los grandes. } \\
\text { Soy } 6 \text { pecados capitales. } \\
\text { \#MuerteYDestruccion } \\
\text { \#ContraGéneros }\end{array}$ & 603 & 20.677 & 2 & 478 & $1 \%$ \\
\hline$@$ mariajamardoc & $\begin{array}{l}\text { María Jamardo - Periodista de } \\
\text { @okdiario. Escribo, sobre todo, } \\
\text { sobre leyes y tribunales. Hablo en } \\
\text { Espejo Público (Antena 3) y esRadio }\end{array}$ & 532 & 33.668 & 3 & 449 & $1 \%$ \\
\hline @_santostrinidad & $\begin{array}{l}\text { Español, buscando el antídoto contra } \\
\text { comunistas, chavistas, podemistas, } \\
\text { separatistas, pro-etarras y anti- } \\
\text { españoles en general. }\end{array}$ & 26.131 & 27.554 & 1 & 311 & $1 \%$ \\
\hline @isaacparejo & $\begin{array}{l}\text { Comunicador, bloguero, redes } \\
\text { sociales }\end{array}$ & 1.084 & 26.195 & 1 & 283 & $1 \%$ \\
\hline @estermunoz85 & $\begin{array}{l}\text { Senadora. Portavoz de Justicia del PP } \\
\text { en el Senado }\end{array}$ & 1.596 & 17.684 & 1 & 257 & $1 \%$ \\
\hline \multirow[t]{2}{*}{ @joveneuropeo } & $\begin{array}{l}\text { Luz para los justos, alegría para los } \\
\text { puros de corazón. } \\
\text { \#IgnacioEcheverría }\end{array}$ & 599 & 38.183 & 1 & 226 & $0,45 \%$ \\
\hline & & & TOTAL & 11 & 3.497 & $7,45 \%$ \\
\hline
\end{tabular}

Fuente: Elaboración propia.

Entre los ocho usuarios más retuiteados de este grupo destacan la senadora Esther Muñoz del Partido Popular, la periodista del portal digital de noticias OKDiario María Jamardo y el bloguero Isaac Parejo. Dado que el anonimato es una de las características distintivas del uso de Internet y las redes sociales digitales, existen cinco perfiles cuya identidad se desconoce. Sabemos poco más que la descripción que dan de sí mismos, por lo que no hay garantías de que uno de ellos no sea un bot. De hecho, al aplicar el "Botometer" de la Universidad de Indiana (2019) a todos estos perfiles, se encontró que había un $22 \%$ de probabilidad de que la cuenta @_santostrinidad estuviera completamente automatizada. El resto, según "Botometer", no eran cuentas automatizadas.

En cuanto al contenido de los tuits de este grupo, en 9 de los 11 encontramos acalorados ataques contra Podemos y su portavoz en el Congreso, Irene Montero. Estos fueron retuiteados 2.971 veces, lo que representa la mitad de los retuits registrados dentro de esta comunidad. En estos tuits notamos varios elementos que se repiten: se acusa al partido Podemos y sus dirigentes de "no respetar los resultados de las urnas" o el estado de derecho, y de "no aceptar las decisiones de los tribunales"; se les tacha de "ignorantes" e "incultos"; Irene Montero es acusada de "irresponsable", de recurrir a 
"titulares fáciles y clichés", y de hablar "sin la menor idea de la ley", lo que asocian con "demagogia y populismo". También condenan al partido por "agitar las calles y llamar al enfrentamiento".

De esta forma cuestionan si Podemos, sus dirigentes y sus simpatizantes son realmente "democráticos" y advierten de la posibilidad de su llegada al poder ("es totalitarismo"), citando a Venezuela y Cuba como ejemplos. Un tuit con contenido audiovisual muestra un vehículo en llamas en medio de una calle, un acto de vandalismo que, sin ningún tipo de información de apoyo, se supone que es responsabilidad directa de los seguidores de Podemos. La persona que publicó el tuit (@marubimo) los presenta como "los muchachos de Coletaborroka", en alusión al Secretario General de Podemos, Pablo Iglesias. Y añade: "¡¡Esto es leninismo bolchevique al más puro estilo Podemos!! ¿No es esto antidemocrático? ¿No es esto anticonstitucional? ¿No es esto una incitación al odio y la violencia?"

Irene Montero también es condenada por supuestamente hacer la vista gorda ante casos en los que "14 extranjeros cometen violación y salen libres", por lo que es tachada de "oportunista cínica que vive del victimismo femenino". Estos ataques contra la portavoz del Congreso de Podemos son llamativos porque no fue la única líder de su partido que expresó su indignación por el fallo del TSJN. El exsecretario de Análisis Estratégico y Cambio Político del partido y también diputado, Íñigo Errejón, también criticó el fallo e incluso consiguió más retuits que Montero, pero esta comunidad de oposición a las protestas no lo menciona en absoluto. Los ataques contra Montero representan el 2,5\% del $8 \%$ del total de RT recaudados de los que esta comunidad era responsable.

Las críticas directas al movimiento feminista se encontraron solo en el 1\% del total, específicamente, en el único tuit del usuario llamado@_santostrinidad, que hace referencia a "jolgorio y regocijo feminazi de indignación con 'La Manada"', antes de agregar un enlace a una noticia que informaba que "siete refugiados" violaron a una niña "brutal y repetidamente durante varios meses". Sobre este punto, se encontró un tono xenófobo en el contenido del 2\% de los tuits. Como conclusión de este apartado, cabe señalar que uno de los tres tuits publicados por la periodista de OKDiario María Jamardo incluye un enlace a su entrevista con el abogado que representa a los cinco integrantes de "La Manada". Sin embargo, esto fue retuiteado solo una vez. De sus tuits, el único que tuvo un impacto real fue el tuit en el que describió a Podemos de la siguiente manera: "No respetan los resultados de las urnas. No aceptan las decisiones de los tribunales. Y, en consecuencia, agitan las calles y llaman al enfrentamiento. Muy democrático..." (443 retweets).

\section{Expertos legales entre dos bloques opuestos}

Si bien su presencia es insignificante entre los retweets, como se refleja en la debilidad de sus conexiones y la falta de centralidad de sus nodos, es interesante analizar la participación de algunos expertos legales encontrados entre los dos bloques opuestos analizados anteriormente, como se ve en la Tabla 3 a continuación.

Tabla 3: Características de los usuarios más retuiteados en la comunidad de expertos legales.

\begin{tabular}{|c|c|c|c|c|c|c|}
\hline & & & & & RTs & \\
\hline Usuarios & Actividad Declarada & Siguiendo & Seguidores & Tweets & $\begin{array}{l}\text { Frecuencias } \\
\text { Absolutas }\end{array}$ & $\%$ \\
\hline @judgethezipper & Juez indignado e inconformista. & 273 & 23.455 & 3 & 424 & $1 \%$ \\
\hline @juristanloqcido & $\begin{array}{l}\text { Somos } 2 \text { eternos estudiantes de } \\
\text { Derecho }\end{array}$ & 377 & 58.500 & 1 & 231 & $0,46 \%$ \\
\hline @ chemadepablo & $\begin{array}{l}\text { Abogado penalista del Bufete Mas } \\
\text { Calvet. Profesor en @ derecho_unav }\end{array}$ & 126 & 23.300 & 2 & 194 & $0,4 \%$ \\
\hline
\end{tabular}


RLCS, Revista Latina de Comunicación Social, 79, 237-262

[Investigación] DOI: 10.4185/RLCS-2021-1502| ISSN 1138-5820| Año 2021

\begin{tabular}{|c|c|c|c|c|}
\hline & $\begin{array}{l}\text { y en @IElaw. Autor de Cuarta } \\
\text { trama [Cuarta Conspiración] }\end{array}$ & & & \\
\hline 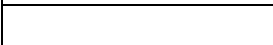 & & TOTAL & 849 & $2 \%$ \\
\hline
\end{tabular}

Fuente: Elaboración propia.

Estos representan el 3,68\% de los nodos y representan el 2\% del número total de RT recogidos. En cuanto al contenido que comparten, la mitad de estos tweets se presentan como un servicio público, compartiendo la sentencia del TSJN "para quien quiera leerlo" (@judgethezipper y @ juristanloqcido), mientras que dos de los tres expertos también lo analizan y/o comentan.

En dos de los tres tuits publicados por @judgethezipper, se enfatiza la complejidad del caso, como lo demuestra (argumenta) la falta de consenso entre los jueces: "Resumen tras dos juicios de \#laManada: 2 jueces, fiscal y examinador Magistrado consideran que fue asalto. 5 jueces consideran que fue abuso. Un juez no encuentra ningún delito probado. Todos, excepto el último, le creen a la víctima". Y concluye: "Y luego intentarán decirnos que es un caso claro y sencillo". Dado que no conocemos la identidad de la persona que se esconde detrás de este perfil, se trata supuestamente de una opinión de un experto, que en todo caso choca con el argumento en defensa de la víctima y, por extensión, con el razonamiento del movimiento feminista y la comunidad crítica del fallo del TSJN.

Sin embargo, es el hilo del penalista Chema de Pablo, analizando la sentencia, el que mejor sirve a los intereses de la comunidad anti-Podemos. De hecho, el nodo de este hilo es el más cercano al grupo azul en el gráfico porque fue más retuiteado por miembros de esta comunidad. En su hilo, Chema de Pablo no solo disecciona paso a paso la sentencia del tribunal, destacando la diferencia entre agresión sexual y abuso sexual, sino que también concluye el hilo con su opinión como experto legal. En primer lugar, señala el límite "débil" entre la influencia indebida y la intimidación en un caso de abuso o agresión sexual. En concreto, según el Código Penal español, influencia indebida (prevalimiento) significa que "hay consentimiento, pero se ha obtenido aprovechando una situación de superioridad", y en base a ello, en lugar de un caso de violación, estamos ante un caso de abuso sexual. Agrega así: "Me gustaría ver un análisis más detallado y preciso de los hechos probados. El fallo cierra el asunto, creo, demasiado rápido y superficialmente".

\section{Discusiones y conclusiones}

Twitter es una red compleja para la expresión de la opinión pública que brinda un foro para personas e instituciones, organizaciones y colectivos, partidos políticos y medios de comunicación (Jivkova, Requeijo \& Padilla, 2017; Barrientos, Caldevilla \& Vargas, 2019; Bernárdez, Padilla \& Sosa, 2019; Cabezuelo \& Manfredi, 2019; Castillo, Díaz \& Caldevilla, 2019; Gorina \& Agadjanian, 2019; Gülel, 2019; Orbegozo, Morales y Larrondo, 2019; Núñez-Puente y Fernandez-Romero, 2019; Molpeceres y Filardo- Llamas, 2020). Con un tema tan controvertido como la violencia de género, y en este caso un juicio por violación en grupo, la difusión de opiniones relacionadas con el fallo del TSJN sobre el caso "La Manada" refleja un rechazo generalizado a la decisión judicial. En concreto, la comunidad que se opone a la pena por abuso sexual en lugar de agresión representa el 40,6\% del total. Esta respuesta negativa fue liderada por la coalición de izquierda Ahora Podemos, por algunos de sus simpatizantes y también por grupos feministas y destacados activistas, entre ellos la periodista Cristina Fallarás.

Esto respalda tres de nuestras hipótesis iniciales: la existencia de una élite política y mediática en el mundo real que ha extendido su influencia al ámbito digital de Twitter, pero que no puede eclipsar la 
influencia de voces que ofrecen puntos de vista alternativos y opuestos, como@vmm7773 (Perra Roja de Satán) o @srtabebi, dos activistas del movimiento feminista con muchos seguidores.

El impacto de las voces que se oponen al establecimiento respalda nuestra tercera hipótesis: que el poder que hoy despliega el feminismo en las redes sociales se sustenta en una sólida base social, con cientos de miles de personas dispuestas a salir a las calles a protestar por decisiones que consideran perjudiciales para los intereses de las mujeres y su derecho a la igualdad y a una vida libre de violencia misógina. La idea de una "justicia patriarcal" que permita a los violadores actuar con impunidad está presente en el 20,72\% de los retuits recogidos. En respuesta al "sesgo misógino" del poder judicial, ocho de los diez usuarios más retuiteados convocaron protestas callejeras $(10,16 \%$ de los RT).

Nuestro análisis de cómo se difundió el hashtag \#LaManada en Twitter el 5 de diciembre de 2018 también revela la presencia de una comunidad (con el $12,11 \%$ de los nodos) vehementemente opuesta a Ahora Podemos y, por extensión, defensiva de la decisión judicial. Acusan a la coalición de izquierda de "no aceptar los resultados de las urnas" ni respetar las decisiones de los tribunales, y ponen en tela de juicio los valores democráticos de sus dirigentes. En los acalorados ataques contra Ahora Podemos, llama la atención que algunas de las críticas más duras (el 2,5\% de los RT capturados) van dirigidas a su portavoz en el Congreso, Irene Montero, aunque no fue la única líder del partido en manifestar su indignación por la decisión del TSJN.

Aunque en un solo tuit se hacen alusiones despectivas al movimiento feminista y sus activistas, hay un tono claramente xenófobo en el 2,5\% de los RT, con mensajes que se centran en las violaciones grupales cometidas por inmigrantes tanto dentro como fuera de España. La importancia que ha adquirido la red social para los profesionales de otros campos (fuera de los ámbitos de la comunicación y la política) se revela en el análisis de una comunidad de expertos legales que ofrecen un servicio público compartiendo noticias sobre fallos judiciales y explicando su contenido.

Finalmente, nuestro análisis de los veintiún usuarios más retuiteados dentro de las tres comunidades estudiadas revela que todos menos uno son influencers importantes en Twitter, con más de 10,000 seguidores. Sin embargo, no todos revelan su verdadera identidad. Un total de 10 de estos 21 usuarios $(47,61 \%)$ mantienen su anonimato mientras difunden sus ideas en la red. De estos, 3 forman parte de la comunidad crítica con el fallo del TSJN; 5 pertenecen al grupo crítico de Ahora Podemos y 2 a la comunidad de expertos legales. Esto resalta el tema del anonimato en línea y en las redes sociales digitales en particular.

El anonimato en estas plataformas tiende a verse como una oportunidad para expresar libremente ideas y opiniones que de otro modo serían imposibles de difundir y que incluso podrían suponer un peligro para la seguridad física y psicológica de quien las difunde. Sin embargo, en la era de la "posverdad", no se puede descartar la posibilidad de que estos perfiles puedan ser cuentas automatizadas creadas simplemente para difundir rumores infundados o desinformación. En nuestro estudio, solo había una cuenta para la cual la probabilidad de automatización completa era tan alta como $22 \%$, que es un porcentaje significativo respaldado por "Botometer" y la transmisión de API Thoarder. Sin embargo, respetar y garantizar el anonimato de estas personas hace más necesario que nunca dotar a los usuarios de estas redes sociales, y de Internet en general, de herramientas para protegerse de la desinformación. 


\section{Bibliografía}

Amnesty International (2018a). Body Politics: A Primer on Criminalization of Sexuality and Reproduction. London: Peter Benenson House.

Amnesty International (2018b). Hablemos del sí. https://www.es.amnesty.org/en-queestamos/blog/historia/articulo/hablemos-del-si/

Ana, A. (2017). The Role of the Feminist Movement Participation during the Winter 2012 Mobilisations in Romania. Europe-Asia Studies, 67(9), 1473-1498. https://doi.org/10.1080/09668136.2017.1395810

Anguí-Sánchez, D.; Cabezuelo-Lorenzo, F. \& Sotelo-González, J. (2019). Innovación tecnológica y social en los nuevos medios digitales norteamericanos. Análisis del caso de Quartz News. Revista Latina de Comunicación Social, (74), 1697-1713. https://doi.org/10.4185/RLCS-2019-1405

Arbatskaya, E. (2019). Discursive activism in the Russian feminist hashtag campaign: the \#ItIsNotAReasonToKill case. Russian Journal of Communication, 11(3), 253-273. https://doi.org/10.1080/19409419.2019.1679663

Armstrong, C. L., \& Mahone, J. (2017). It's on us. The Role of Social Media and Rape Culture in Individual Willingness to Mobilize Against Sexual Assault. Mass Communication and Society, 20(1),

92-115.

https://www.tandfonline.com/doi/abs/10.1080/15205436.2016.1185127?needAccess=true\&

Atencio, G. (ed.) (2018). Agresiones sexuales múltiples en España. Informe 2016-2018 (Multiple sexual aggressions in Spain. 2016-2018 Report). https://geoviolenciasexual.com/agresionessexuales-multiples-en-espana-informe-2016-2018/

Aune, K., \& Holyoak, R. (2018). Navigating the Third Wave: Contemporary UK Feminist Activists and Third-Wave Feminism. Feminist Theory, 19(2), 183-203. https://doi.org/10.1177/1464700117723593

Baer, H. (2016). Redoing Feminism: Digital Activism, Body Politics, and Neoliberalism. Feminist Media Studies, 16(1), 17-34. https://www.tandfonline.com/doi/abs/10.1080/14680777.2015.1093070

Barker, R. (2018). Trapped in the Filter Bubble? Exploring the Influence of Google Search on the Creative Process. Journal of Interactive Advertising, 18(2), 85-95. https://doi.org/10.1080/15252019.2018.1487810

Barrientos-Báez, A.; Caldevilla-Domínguez, D. \& Vargas-Delgado, J. J. (2019). El protocolo, la puesta en escena y la persuasión en los debates políticos televisados. Redmarka. Revista De Marketing Aplicado, 23(3), 17-27. https://doi.org/10.17979/redma.2019.23.3.5872

Bastos, M. T., \& Mercea, D. (2015). Serial Activists: Political Twitter beyond Influential and the $\begin{array}{lllll}\text { Twittertariat. New Media \& } \quad \text { Society, } & 18(10), & \text { 2359-2378. }\end{array}$ https://doi.org/10.1177/1461444815584764 
RLCS, Revista Latina de Comunicación Social, 79, 237-262

[Investigación] DOI: 10.4185/RLCS-2021-1502| ISSN 1138-5820| Año 2021

Bechmann, A. \& Nielbo, K. L. (2018). Are We Exposed to the Same "News" in the News Feed? Digital Journalism, 6(8), 990-1002. https://doi.org/10.1080/21670811.2018.1510741

Berber, N. (2017). Writing the Rape in Post-Conflict Societies of the 1990s: John M. Coetzee and Slavenka Drakulić. Critique: Studies in Contemporary Fiction, 59(1), 103-114. https://doi.org/10.1080/00111619.2017.1354811

Bermudez, S., \& Johnson, R. (2018). A New History of Iberian Feminism. Toronto: University of Toronto Press.

Bernárdez-Rodal, A. \& Moreno-Segarra, I. (2017). La maternidad contemporánea entre la catástrofe y el sacrificio. Un análisis de Lo imposible. L'Atalante. Revista de estudios cinematográficos, 23, 171-186.

Bernárdez-Rodal, A., \& Padilla-Castillo, G. (2018). Female filmmakers and women's representation in Spanish commercial cinema (2001-2016). Revista Latina de Comunicación Social, (73), 12471266. https://doi.org/10.4185/RLCS-2018-1305

Bernárdez-Rodal, A., \& Padilla-Castillo, G. (2019). "Feminist leadership in hashtags: viral labels of the new political and social debate in Spain," in A. Alonso, \& T. Langle-de-Paz (eds.), The Time Is Now. Feminist Leadership for a New Era. Buenos Aires \& Paris: UNESCO, 40-50. https://en.unesco.org/news/e-book-time-now-feminist-leadership-new-era-global-network-unescochairs-gender

Bernádez-Rodal, A.; Padilla-Castillo, G., \& Sosa-Sánchez, R. P. (2019). From Action Art to Artivism on Instagram: Relocation and instantaneity for a new geography of protest. Catalan Journal of Communication and Cultural Studies, 11(1), 23-37. https://doi.org/10.1386/cjcs.11.1.23_1

Bernárdez-Rodal, A. \& Serrano-Fuertes, M. (2018). Lo personal es político: un bebé en la sesión de constitución de las cortes generales. El tratamiento televisivo del caso de Carolina Bescansa y su hijo (13 de enero de 2016). Vivat Academia Revista de Comunicación, (142), 79-96. DOI: https://doi.org/10.15178/va.2018.142.79-96

Botometer (2019). Network Science Institute (IUNI) and the Center for Complex Networks and Systems Research (CNetS) at Indiana University. https://botometer.iuni.iu.edu/\#!/

Brennan, G. (2018). How Digital Media Reshapes Political Activism: Mass Protests, Social Mobilization, and Civic Engagement. Geopolitics, History, and International Relations, 10(2), 7681. https://doi.org/10.22381/GHIR102201810

Cabezuelo-Lorenzo, F. \& Manfredi, J. L. (2019). Posverdad, fake-news y agenda política en el discurso de Trump en Twitter. Historia y comunicación social, 24(2), 449-483. https://dx.doi.org/10.5209/hics.66291

Caldevilla-Domínguez, D.; Rodríguez-Terceño, J.; Barrientos-Báez, A. (2019). El malestar social a través de las nuevas tecnologías: Twitter como herramienta política. Revista Latina de Comunicación Social, (74), 1264-1290. https://doi.org/10.4185/RLCS-2019-1383-66 
RLCS, Revista Latina de Comunicación Social, 79, 237-262

[Investigación] DOI: 10.4185/RLCS-2021-1502| ISSN 1138-5820| Año 2021

Caldevilla-Domínguez, D. \& García-García, E. (2020). Profesionales y posverdad: La responsabilidad colectiva como arma contra la falacia digitalizada. aDResearch ESIC, (21), 7083. https://doi.org/10.7263/adresic-021-04

Campillo, I. (2019). If we stop, the world stops': the 2018 feminist strike in Spain. Social Movement Studies, 18(2), 252-258. https://doi.org/10.1080/14742837.2018.1556092

Castillo-Durán, J. L.; Díaz-Mendoza, C. A., \& Caldevilla-Domínguez, D. (2019). El peso de la 'publicity' gubernamental en México en la prensa local. La imagen del gobernador de Puebla, 2014-2015. Estudios Sobre El Mensaje Periodístico, 25(3), 1339-1356. DOI: https://doi.org/10.5209/esmp.66991

Cedeira, B. (2018). El Tribunal Superior de Navarra mantiene la pena a 'La Manada': no hubo violación. El Español. https://www.elespanol.com/reportajes/20181205/tribunal-superior-navarramantiene-manada-no-violacion/358464363_0.html

Cense, M.; Bay-Cheng, L., \& van Dijk, L. (2018). Do I Score Points if I Say "No"?: Negotiating Sexual Boundaries in a Changing Normative landscape. Journal of Gender-Based Violence, 2(2), 277-291. https://doi.org/10.1332/239868018X15266363560443

CETS (2011). Convention on Preventing and Combating Violence against Women and Domestic Violence. Council of Europe Treaty Series, 210, 25. https://rm.coe.int/168008482e

Cole, K. K. (2015). It's Like She's Eager to be Verbally Abused: Twitter, Trolls, and (En) Gendering Disciplinary Rhetoric. Feminist Media Studies, 15(2), 356-358. https://doi.org/10.1080/14680777.2015.1008750

Congosto, M. (2017). Arquitectura de T-hoarder. https://github.com/congosto/thoarder/wiki/Arquitectura-de-t-hoarder

Congosto, M.; Basanta-Val, P., \& Sanchez-Fernandez, L. (2017). T-Hoarder: A Framework to Process Twitter Data Streams. Journal of Network and Computer Applications, 83, 28-39. https://doi.org/10.1016/j.jnca.2017.01.029

Congosto, M. (2018). Digital Sources: A Case Study of the Analysis of the Recovery of Historical Memory in Spain on the Social Network Twitter. Culture \& History Digital Journal, 7(2), 1-19. https://doi.org/10.3989/chdj.2018.015

Cooke, S. (2019). Power, secularism and divorce: women's rights in Egypt and Iran. National Identities, latest articles. https://doi.org/10.1080/14608944.2019.1634034

Dehesa, R. de la (2018). Social medicine, feminism and the politics of population: From transnational knowledge networks to national social movements in Brazil and Mexico. Global $\begin{array}{llr}\text { Public } \quad \text { Health, } & \text { 803-816. }\end{array}$ https://www.tandfonline.com/doi/full/10.1080/17441692.2018.1443486

De-Miguel-Pascual, R.; Parratt-Fernández, S.; Berganza, R. (2019). Las percepciones de las mujeres periodistas sobre su trabajo. La variable género en la cultura profesional. Revista Latina de Comunicación Social, (74), 1818-1833. https://doi.org/10.4185/RLCS-2019-1412-95 
RLCS, Revista Latina de Comunicación Social, 79, 237-262

[Investigación] DOI: 10.4185/RLCS-2021-1502| ISSN 1138-5820| Año 2021

Doria, J.; Álvarez, P. \& Valdés, I. (2018). El Tribunal Superior de Navarra confirma la condena de La Manada a nueve años de cárcel por abuso sexual. El País. https://elpais.com/sociedad/2018/12/05/actualidad/1543995494_456176.html

El Periódico (2018). 'La Manada': la confirmación de la sentencia vuelve a desatar la indignación. El Periódico. https://www.elperiodico.com/es/sociedad/20181205/manada-reacciones-sentencia$\underline{\text { tsjn-7185437 }}$

Etura-Hernández, D.; Martín-Jiménez, V. \& Ballesteros-Herencia, C. A. (2019). La comunidad universitaria, frente a la igualdad de género: un estudio cuantitativo. Revista Latina de Comunicación Social, (74), 1781-1800. https://doi.org/10.4185/RLCS-2019-1410-93

Europa Press (2018). La sentencia de La Manada, entre las peores del año en todo el mundo sobre igualdad. https://www.europapress.es/epsocial/igualdad/noticia-sentencia-manada-peores-anotodo-mundo-igualdad-20181204174609.html

Fan, L-N.; Wu, M-Y.; Wall, G. \& Zhou, Y. (2019). Community support for tourism in China's Dong ethnic villages. Journal of Tourism and Cultural Change, 18. https://doi.org/10.1080/14766825.2019.1659283

Fernández-Romero, D. (2019). Spain's campaigns against gender violence: the effect on abused women's identities from the victim-agent dichotomy. Journal of Gender Studies, latest articles. https://doi.org/10.1080/09589236.2019.1596786

Fontenla-Pedreira, J.; Rúas-Araújo, J. \& Conde-Vázquez, E. (2020). Audiencia en redes sociales de los debates televisados en las elecciones generales de abril de 2019. Revista Latina de Comunicación Social, 76, 1-16. https://www.doi.org/10.4185/RLCS-2020-1434

García-Orosa, B. \& Gallur-Santorun, S. (2019). La presencia de la mujer en las informaciones de los cibermedios europeos de España, Italia, Gran Bretaña, Portugal y Francia. Revista Latina de Comunicación Social, (74), 403-417. https://doi.org/10.4185/RLCS-2019-1337

Haim, M.; Graefe, A. \& Brosius, H. B. (2018). Burst of the Filter Bubble? Digital Journalism, 6(3), 330-343. https://doi.org/10.1080/21670811.2017.1338145

Harp, D.; Grimm, J. \& Loke, J. (2018). Rape, Storytelling and Social Media: How Twitter Interrupted the News Media's Ability to Construct Collective Memory. Feminist Media Studies, 18(6), 979-995. https://doi.org/10.1080/14680777.2017.1373688

Harper, C. A.; Franco, V. \& Wills, M. (2019). Excusing and Justifying Rape Cognitions in Judgments of Sexual Coercitive Datint Scenarios. Sexual Abuse. https://doi.org/10.1177/1079063219825869

Hasunuma, L. \& Shin, K. (2019). \#MeToo in Japan and South Korea: \#WeToo, \#WithYou. Journal of Women, Politics \& Policy, 40(1), 97-111. https://doi.org/10.1080/1554477X.2019.1563416

Hatch, M. (2019). Campaigning for the rights of women workers in South Africa: Michelle Hatch speaks to Pat Horn. Empowering women for gender equity, 33(4), 103-110 https://doi.org/10.1080/10130950.2019.1674676 
Herrera, C. \& Agoff, M. C. (2018). The Intricate Interplay between Victimization and Agency: Reflections on the Experiences of Women Who Face Partner Violence in Mexico. Journal of Research in Gender Studies, 8(1), 49-72. https://doi.org/10.22381/JRGS8120183

Hsu, V. J. (2019). (Trans)forming \#MeToo: Toward a Networked Response to Gender Violence. Women's Studies in Communication, 269-286. https://doi.org/10.1080/07491409.2019.1630697

Galletero-Campos, B.; López-Cepeda, A. M. \& Martínez-Rodrigo, A. (2020). Estudio comparativo de la centralidad y uso de Twitter de las televisiones autonómicas en los debates electorales del 26M. Revista Latina de Comunicación Social, 76, 97-119. https://www.doi.org/10.4185/RLCS$\underline{2020-1439}$

Gephi.org (2020). Features. https://gephi.org/features/

Gorina, E., \& Agadjanian, V. (2019). Belonging and Political Participation: Evidence from the 2011 President Election in Kyrgyzstan. Europe-Asia Studies, 71(9), 1562-1583. https://doi.org/10.1080/09668136.2019.1665168

Gray-Hawkins, M. (2018). Collective Movements, Digital Activism, and Protest Events: The Effectiveness of Social Media Concerning the Organization of Large-Scale Political Participation. Geopolitics, History, and International Relations, 10(2), 64-69. https://doi.org/10.22381/GHIR10220188

Gülel, D. (2019). Feminist movement and law-making in Turkey: a critical appraisal from 1998 to 2018. Women's History Review, latest articles. Retrieved from https://doi.org/10.1080/09612025.2019.1695357

Jivkova-Semova, D.; Requeijo-Rey, P. \& Padilla-Castillo, G. (2017). Usos y tendencias de Twitter en la campaña a elecciones generales españolas del 20D de 2015: hashtags que fueron trending topic. El profesional de la información, 26(5), 824-837. https://doi.org/10.3145/epi.2017.sep.05

Kamenou, N. (2019). Feminism in Cyprus: women's agency, gender, and peace in the shadow of nationalism. International Feminist Journal of Politics, latest articles. https://doi.org/10.1080/14616742.2019.1687000

Kanai, A. \& McGrane, C. (2020). Feminist filter bubbles: ambivalence, vigilance and labour. Information, Communication \& Society, online, $1-16$. https://doi.org/10.1080/1369118X.2020.1760916

Kirby, P. (2015). Ending Sexual Violence in Conflict: The Preventing Sexual Violence Initiative and Its Critics. International Affairs, 91(3), 457-472. https://doi.org/10.1111/1468-2346.12283

Klinger, U. \& Svensson, J. (2014). The emergence of network media logic in political communication: A theoretical approach. New media and society, 17(8), 1241-1257. https://doi.org/10.1177/1461444814522952

Klinger, U. \& Svensson, J. (2016). Network media logic. In: A. Bruns, G. Enli, E. Skogerbö, A. Larsson \& C. Christensen (Eds.), Routledge companion to social media and politics (23-38). New York: Routledge. 
Lăzăroiu, G. (2018). Participation Environments, Collective Identities, and Online Political Behavior: The Role of Media Technologies for Social Protest Campaigns. Geopolitics, History, and International Relations, 10(2), 58-63. https://doi.org/10.22381/GHIR10220187

Levi, S. (Ed.) (2019). \#FakeYou, fake news y desinformación. Barcelona: Rayo Verde Editorial.

Lin, Z., \& Yang, L. (2019). Individual and collective empowerment: Women's voices in the \#MeToo movement in China. Asian Journal of Women's Studies, 25(1), 117-131. https://doi.org/10.1080/12259276.2019.1573002

Marchand, M. H. (2014). Engendering Transnational Movements/Transnationalizing Women's and Feminist Movements in the Americas. Latin American Policy, 5(2), 180-192. https://doi.org/10.1111/lamp.12056

Martínez-Pleguezuelos, A. J.; Alcalde-Peñalver, E. \& Santamaría-Urbieta, A. (2020). Retos ante la reescritura del cuerpo sexuado de la mujer y la prostitución femenina: estudio de caso. Vivat Academia Revista de Comunicación, (150), 59-80. https://doi.org/10.15178/va.2020.150.59-80

McGlynn, C. (2017). Rape Trials and Sexual History Evidence: Reforming the Law on Third-Party Evidence. The Journal of Criminal Law, 81(5), 367-392. https://doi.org/10.1177/0022018317728824

Melo, D. F. (2016). Women's mobilisation in the Portuguese revolution: context and framing strategies. Social Movement $\quad$ Studies, $\quad$ 15(4), https://doi.org/10.1080/14742837.2016.1149460

Mendes, K.; Keller, J., \& Ringrose, J. (2018). Digitized Narratives of Sexual Violence: Making Sexual Violence Felt and Known Through Digital Disclosure. New Media \& Society, 21(6), 16901310. https://doi.org/10.1177/1461444818820069

Ministry of the Interior (2018). Balance de Criminalidad. Primer Trimestre de 2018 (Crime Balance First Quarter of 2018). http://www.interior.gob.es/documents/10180/8736571/informe+balance+criminalidad+1\%C2\%B A\%20trimestre+2018.pdf/4b88d3df-c9d1-4b0f-b938-c694efd7e6e5

Mojica-Acevedo, E. C.; Espinel-Rubio, G. A. \& Botero-Montoya, L. H. (2019). Historias de vida como método de investigación en Comunicación Social. El caso de mujeres periodistas en San José de Cúcuta (Colombia). Revista Latina de Comunicación Social, (74), 347-359. https://doi.org/10.4185/RLCS-2019-1334

Molpeceres-Arnáiz, S. \& Filardo-Llamas, L. (2020). Llamamientos feministas en Twitter: ideología, identidad colectiva y reenmarcado de símbolos en la huelga del $8 \mathrm{M}$ y la manifestación contra la sentencia de "La Manada". Dígitos. Revista de Comunicación Digital, (6) 55-78. https://doi.org/10.7203/rd.v1i6.181

Moreno-Segarra, I. \& Bernárdez-Rodal, A. (2017). How to be a choni. Tutorial videos, class and gender in Spain's economic recession. Catalan journal of communication \& cultural studies, 9(2), 265-284. https://doi.org/10.1386/cjcs.9.2.265_1 
Núñez-Puente, S. \& Fernández-Romero, D. (2019). Posverdad y victimización en Twitter ante el caso de La Manada: propuesta de un marco analítico a partir del testimonio ético. Investigaciones Feministas, 10(2), 385-398. https://doi.org/10.5209/infe.66501

Ojer, P. (2018). El TSJN confirma los abusos y la no agresión de La Manada. ABC. https://www.abc.es/sociedad/abci-tsjn-mantiene-pena-manada-201812050834_noticia.html

Orbegozo-Terradillos, J.; Morales-i-Grass, J. \& Larrondo-Ureta, A. (2019). Feminismos indignados ante la justicia: la conversación digital en el caso de La Manada. IC: Revista Científica de Información y Comunicación, (16), 211-247. https://dx.doi.org/10.12795/IC.2019.i01.08

Ortiz, A. M. \& Álvarez, R. J. (2018). La Justicia navarra confirma la condena de nueve años por abuso sexual para los miembros de La Manada. El Mundo. https://www.elmundo.es/espana/2018/12/05/5c06d8d3fc6c8327258b4602.html

Padilla-Castillo, G. \& Oliver-González, A. B. (2018). Instagramers e influencers. El escaparate de la moda que eligen los jóvenes menores españoles. aDResearch ESIC, (18), 42-59. https://doi.org/10.7263/adresic-018-03

Pariser, E. (2011). The Filter Bubble: What The Internet Is Hiding From You. London: Penguin.

Phillips, J. \& Yi, J. (2019). Queer Communities and Activism in South Korea: Periphery-Center Currents. Journal of Homosexuality, latest articles. https://doi.org/10.1080/00918369.2019.1616432

Pradhan, A. (2019). Raped, outraged, ravaged: race, desire, and sex in the Indian empire. Porn Studies, latest articles. https://doi.org/10.1080/23268743.2019.1597639

Puschmann, C. (2019). Beyond the Bubble: Assessing the Diversity of Political Search Results. Digital Journalism, 7(6), 824-843. https://doi.org/10.1080/21670811.2018.1539626

Quilter, J. (2016). Rape Trials, Medical Texts and the Threat of Female Speech: The Perverse Female Rape Complainant. Law Text Culture, 19, 231-270. https://ro.uow.edu.au/ltc/vol19/iss1/11

Remacha, B. (2018). Nuevas manifestaciones contra la "justicia patriarcal" tras la sentencia de 'la manada' insistiendo en que "no es abuso, es violación". Eldiario.es. https://www.eldiario.es/sociedad/Concentracion-manada-madrid-sentencia_0_843066678.html

Rone, J. (2019). Fake profiles, trolls, and digital paranoia: digital media practices in breaking the Indignados movement. Social Movement Studies. https://doi.org/10.1080/14742837.2019.1679108

Ruiz-del-Olmo, F. J. \& Bustos-Díaz, J. (2020). Las imágenes publicadas en Twitter como forma de comunicación política. El caso de las elecciones generales del año 2016 en España. Revista Latina de Comunicación Social, (75), 313-326. https://www.doi.org/10.4185/RLCS-2020-1428

Savory, R. (2019). Together, alone? Performance, protest and digital proximities in India's Blank Noise feminist campaign. International Journal of Performance Arts and Digital Media, 15(3), 295-310. https://doi.org/10.1080/14794713.2019.1671696 
Scarborough, W. J. (2018). Feminist Twitter and Gender Attitudes: Opportunities and Limitations to Using Twitter in the Study of Public Opinion. Socius: Sociological Research for a Dynamic World, 4(1). https://doi.org/10.1177/2378023118780760

Seperak-Viera, R. A.; Cerellino, L. P.; Ochoa-Luna, J. E.; Torres-Valer Basauri, A. P. \& DianderasCáceres, C. M. (2019). Maternidad en Perú a través del uso del Sentiment Analysis en Facebook. Revista Latina de Comunicación Social, (74), 1031-1055. https://doi.org/10.4185/RLCS-2019$\underline{1370-53}$

Sinha-Roy, M. (2018). Inside/out: women's movement and women in movements. South Asian History and Culture, 9(4), 420-434. https://doi.org/10.1080/19472498.2018.1535544

Soysa, L. \& Zipp, S. (2019). Gender equality, sport and the United Nation's system. A historical overview of the slow pace of progress. Sport in Society, 22(11), 1783-1800. https://doi.org/10.1080/17430437.2019.1651018

Stubbs-Richardson, M.; Rader, N. E. \& Cosby A. G. (2018). Tweeting Rape Culture: Examining Portrayals of Victim Blaming in Discussions of Sexual Assault Cases on Twitter. Feminism \& Psychology, 28(1), 90-108. https://doi.org/10.1177/0959353517715874

Tableau.com (2020). Tableau Desktop. https://www.tableau.com/es-es/products/desktop

Tapia-Frade, A. \& Del-Toro-Acosta, A. (2019). Semidesnudo, género y otros factores en publicidad televisiva. Un acercamiento desde la neurociencia. Vivat Academia Revista de Comunicación, (147), 1-21. DOI: https://doi.org/10.15178/va.2019.147.1-21

Williams, B. M., Christopher, K. \& Sinski, J. (2017). Who Doesn't Want to Be This Hot Mom?: Celebrity Mom Profiles and Mothers' Accounts of Their Postpartum Bodies. SAGE Open. https://doi.org/10.1177/2158244017720562

Worsley, J. D., Wheatcroft, J. M., Short, E. \& Corcoran, R. (2017). Victims' Voices: Understanding the Emotional Impact of Cyberstalking and Individuals' Coping Responses. SAGE Open. https://doi.org/10.1177/2158244017710292

\section{AUTORES:}

\section{Asunción Bernárdez-Rodal}

Universidad Complutense de Madrid. España.

Catedrática y Directora del Instituto de Investigaciones Feministas de la Universidad Complutense de Madrid (UCM). Profesora de género y comunicación, semiótica de los medios de comunicación e información y teoría de la información en la Facultad de Ciencias de la Información. Doctora en Periodismo y Licenciada en Filología Hispánica por la Universidad Complutense de Madrid (UCM). Autora de numerosos trabajos de investigación internacionales de alto impacto relacionados con el análisis de discursos de género, tanto textuales como audiovisuales. Autora del libro Mujeres en medio(s): Propuestas para analizar la comunicación masiva con perspectiva de género (Editorial Fundamentos, 2015), Violencia de género y sociedad: una cuestión de poder y Don Quijote, el lector por excelencia.

asbernar@ucm.es

Índice H: 12 
Orcid ID: https://orcid.org/0000-0003-4081-0035

Google Scholar: https://scholar.google.com/citations?user=TOKIVQEAAAAJ\&hl=es

ResearchGate: https://www.researchgate.net/profile/Asuncion_Bernardez_Rodal

Scopus ID: https://www.scopus.com/authid/detail.uri?authorId=38261711200

Academia.edu: https://ucm.academia.edu/ASUNCIONBERNARDEZRODAL

\section{Nuria López-Priego}

Universidad Complutense de Madrid. España.

Doctorado en Periodismo por la Universidad Complutense de Madrid y Licenciado en Periodismo por la Facultad de Ciencias de la Información de la Universidad de Sevilla. Entre 2006 y 2017 ha desarrollado su actividad profesional como redactora en el diario provincial Diario Jaén, cubriendo entre 2012 y 2017 información sobre política y gestión municipal. Como periodista, ha ganado el Premio de Periodismo contra la Violencia de Género 2017 del Instituto de la Juventud (Injuve) y el de Periodismo y Comunicación Local de la Diputación Provincial de Jaén en 2011. Desde 2017 es candidata a doctorado en Periodismo en la Universidad Complutense de Madrid (UCM). Investiga el liderazgo político mediado en medios convencionales, nativos digitales y redes sociales con perspectiva de género.

nurlop03@ucm.es

Orcid ID: https://orcid.org/0000-0003-2683-8322

\section{Graciela Padilla-Castillo}

Universidad Complutense de Madrid. España.

Coordinadora del programa de Licenciatura en Periodismo de la Facultad de Ciencias de la Información de la Universidad Complutense de Madrid (UCM). Miembro del Instituto de Investigaciones Feministas (UCM). Doctora en Ciencias de la Información (2010, con mención honorífica) por la Universidad Complutense de Madrid y Licenciada en Periodismo y Comunicación Audiovisual (2006, con premio de grado destacado). Catedrática Acreditada. Becaria postdoctoral en la Universidad de California Los Ángeles (UCLA) y experta invitada en estudios de género en la Benemérita Universidad Autónoma de Puebla (BUAP, México). Sus intereses de investigación se centran en la teoría de la información, la ética y la deontología de la comunicación, la ficción televisiva y los estudios de género. Autora y co-autora de un centenar de capítulos de libros y artículos académicos publicados en revistas de alto impacto. Ha coordinado más de 10 trabajos colectivos y ha participado en más de 30 proyectos de investigación y docencia-innovación competitivos y privados. gracielp@ucm.es

\section{Índice H: 11}

Orcid ID: https://orcid.org/0000-0003-1393-4817

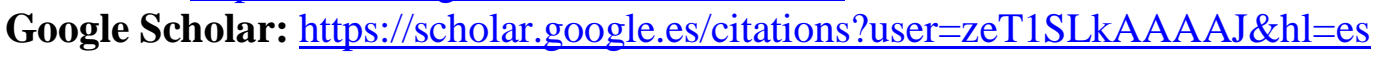

ResearchGate: https://www.researchgate.net/profile/Graciela_Padilla_Castillo

Scopus ID: https://www.scopus.com/authid/detail.uri?authorId=55580259900

Academia.edu: https://ucm.academia.edu/GracielaPadillaCastillo 